\title{
Estudo sôbre a variação da produção leiteira na Raça Holandesa Malhada de Preto
}

\author{
FREDERICO PIMENTEL GOMES \\ Assistente e Livre-Docente de Matemática \\ ARISTEU M. PEIXOTO \\ Assistente de Zootecnia (5². cadeira) \\ Escola Superior de Agricultura "Luiz de Queiroz" \\ Universidade de São Paulo
}

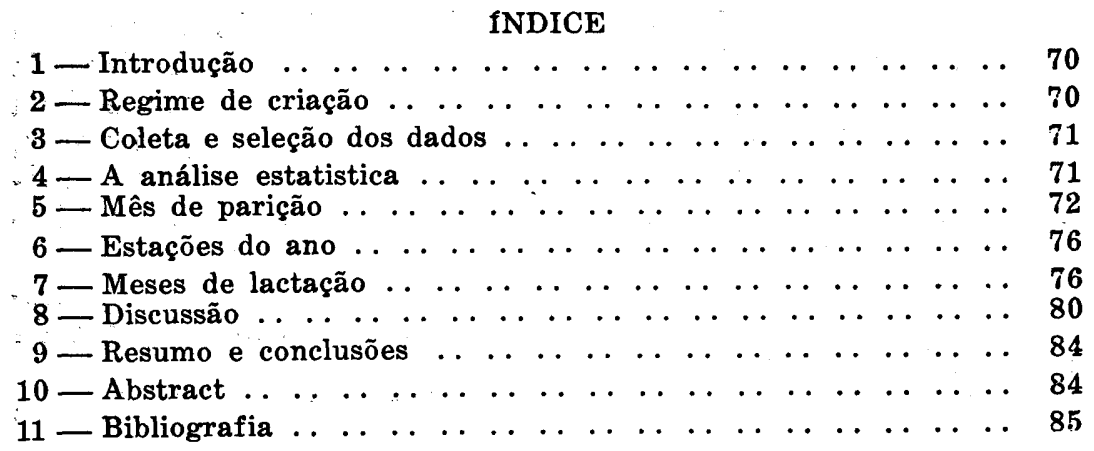




\section{1 - INTRODUÇÃO}

A produção qualitativa e quantitativa de leite sofre a influência de uma série de fatores, uns que dizem respeito ao próprio animal, tais como a hereditariedade, raça, idade, individualidade, período de lactação, época de parição, etc., e outros que se referem às condições externas, como sejam: meio ambiente, tratamento, alimentação, etc.

Estudando a influência das condiçôes ambientais sôbre a secreção láctea, PIMENTEL GOIMES (18) analisou estatisticamente dados relativos à porcentagem de materia graxa do rebanho holandês do Posto Zootécnico da Escola Superior de Agricultura "Luiz de Queiroz". No presente trabalho, que tem por finalidade principal completar aquêle outro, săo estudados alguns fatores que influem sôbre o rendimento da produção leiteira, especialmente a época de parição.

O critério utilizado na escolha dos dados aproveitáveis e a marcha seguida na análise estatística são análogos aos que se adotaram no trabalho citado.

\section{2 - REGIME DE CRIAÇÃO}

As vacas da raça Holandesa Malhada de Preto do Pôstu Zootécnico "Luiz de Queiroz" são criadas em regime de meia estabulação. Recolhidas ao estábulo às $61 / 2$ horas, aí permanecem o dia todo, só saindo às $161 / 2$ horas para o pasto, onde passam a noite. Ficam, assim, abrigadas durante as horas mais quentes do dia, cuidado êste indispensável para o êxito na exploração leiteira com animais de raça pura, em nosso meio.

São realizadas duas ordenhas diárias, pelo processo manual, a primeira às 7 horas da manhã e a sergunda às 15 horas e 30 minutos. O aleitamento dos bezerros é feito artificialmente, com base no leite desnatado.

Durante a ordenha da manhã, é fornecida às vacas uma mistura de farelos (concentrados e volumosos) com cêrca de $15 \%$ de proteina digestível. Às 8 horas, mais ou menos, é dada a primeira refeição de volumosos que consta de capim verde, na época das chuvas, e pontas de cana, silagem (principalmente de milho) ou mandioca, durante o período de sêca. Às 2 horas da tarde, as vacas recebem água, e, a seguir, nova refeição de volumosos. As melhores produtoras e as que estão em período de gestação adiantada recebem, ainda, mais uma porção da mistura de farelos.

As novilhas são cobertas depois dos 2 anos de idade, e a 
cobertura das vacas se processa cerca de 3 meses depois da parição.

As pastagens são constituídas principalmente por capim gordura ou catingueiro (Melinis minutiflora Pal. de Beauv.)

A aptidão medíocre do rebanho inicial, aliada a uma consanguinidade sempre crescente, talvez sejam as causas da produção relativamente baixa observada.

\section{3 - COLETA E SELEÇÃO DOS DADOS}

Os dados foram obtidos nos livros de Registro de Produção, do Pôsto Zootécnico "Luiz de Queiroz". As vacas foram separadas com base no mês de parição, e obtivemos, dentro do período de 1931-1949, quinze parições para cada mês do ano, perfazendo um total de 180 . Na escolha dos animais, procuramos, sempre que possível, evitar vacas primíparas, visto que, em geral, a primeira lactação não corresponde à verdadeira produção da fêmea leiteira. Desprezamos, também, os períodos de lactação correspondentes ao fim da vida produtiva das vacas, pela mesma razão anterior.

Afim de diminuir a influência da variação individual, demos preferência a diferentes períodos de lactação de uma mesma vaca.

A produção das vacas se refere a 300 dias de latação, isto é, consideramos dez meses de trinta dias, a partir da fase colostral. Como eram 180 períodos de lactação, o número de dados colhidos e analisados subiu a 1.800 .

Afim de estudar a influência das estações, dividimos as meses do ano em quatro grupos, designados : primavera (outubro, novembro e dezembro), verão (janeiro, fevereiro e março), outono (abril, maio e junho) e inverno (julho, agosto e setembro).

\section{4 - A ANALISE ESTATísticA}

$\mathrm{Na}$ análise da variância resolvemos isolar os efeitos das seguintes causas de variação:

a) Lactações distintas, de um mesmo animal ou de animais diferentes;

b) Mês de parição; 
c) Meses de lactação, de 30 dias cada um, contados a partir do desaparecimento do colostro;

d) Estações do ano.

Era nossa intenção considerar no item $d$, o mês do anc, mas o fato de os meses de lactação considerados não concordarem, em geral, com o mês civil, isso não foi possível. Tratando-se, porém, das estações do ano, isto é, de 3 meses consecutivos, não pode haver objeção, pois será desprezível a influência de poucos dias de diferença num total de noventa dias.

Os resultados obtidos constam do quadro seguinte:

\begin{tabular}{l|r|r|c}
\hline Causa de variação & $\begin{array}{c}\text { Soma dos } \\
\text { quadrados }\end{array}$ & $\begin{array}{c}\text { Grau de } \\
\text { liberdade }\end{array}$ & Erro \\
\hline \begin{tabular}{l|l|l} 
1. Lactações (den- \\
tro do mês de \\
parição)
\end{tabular} & & & \\
2. Mês de parição & $8.591 .597,35$ & 168 & $226^{* * *}$ \\
3. Meses de lacta- & $844.511,59$ & 11 & $277^{* * *}$ \\
tação (de 30 & & & \\
dias) & $7.196 .168,10$ & 9 & $894^{* * *}$ \\
4. Estações do ano & $961.479,26$ & 3 & $566^{* * *}$ \\
5. Resíduo & $2.145 .718,88$ & 1608 & 36,5 \\
\hline \multicolumn{1}{|c|}{ Total } & $19.739 .475,13$ & 1799 & \\
\hline
\end{tabular}

Os três asteriscos indicam significação para $1 \%$ em relação ao êrro residual.

São particularmente importantes os ítens 2,3 e 4 , que passaremos a discutir com mais detalhe.

\section{5 -- MÊS DE PARIÇÃO}

As médias de produção de leite de acôrdo com o mês de parição, constam do quadro seguinte, onde aparecem também dados referentes à respectiva precipitação pluviométríca. 


\begin{tabular}{l|c|c}
\hline Meses de parição & $\begin{array}{c}\text { Médias de } \\
\text { produção }\end{array}$ & $\begin{array}{c}\text { Queda pluviométrica } \\
\text { média em Piracicaba } \\
(1914-1938)\end{array}$ \\
\hline Janeiro & 251,7 & 227,0 \\
Fevereiro & 245,9 & 251,2 \\
Março & 250,5 & 114,8 \\
Abril & 258,9 & 52,3 \\
Maio & 296,6 & 36,0 \\
Junho & 288,6 & 42,6 \\
Julho & 278,7 & 22,2 \\
Agosto & 320,8 & 33,3 \\
Setembro & 264,5 & 72,7 \\
Outubro & 258,4 & 85,9 \\
Novembro & 281,6 & 127,9 \\
Dezembro & 255,4 & 200,5 \\
\hline
\end{tabular}

O êrro de cada uma dessas médias parciais é :

$$
\sigma \overline{\mathrm{v}}=\frac{36,5}{\sqrt{150}}=2,98
$$

O êrro da média gẹral, $\overline{\bar{v}}=270,99$, é :

$$
\sigma \overline{\bar{v}}=\frac{36,5}{\sqrt{1.800}}=0,86
$$

Logo, o êrro da diferença entre u'a média parcial e a média geral será :

$$
\sigma \text {, dif. }=\sqrt{(2,98)^{2}+(0,86)^{2}}=3,10 .
$$

Verifica-se logo, a partir dêste valor, que, uma vez adotado o limite de $1 \%$ de probabilidade, as médias de produção, correspondentes às parições de janeiro, fevereiro, março, abril e outubro sã̀o significativamente inferiores à média geral. Ao contrário, as médias correspondentes às parições dé maio, junho, agosto e novembro, são superiores à média geral. O gráfico 1 , que indica os limites de $5 \%, 1 \%$ e $1 \%$ o de probabilidade dá uma idéia mais precisa dos resultados. 
O gráfico 1 nos sugere a reunião dos meses do ano em relação a parição, em 3 épocas distintas : uma, altamente favorável à produção leiteira, inclui os meses de maio, junho, julho e agosto; outra, muito desfavorável, abrange os meses de dezembro, janeiro, fevereiro, março e abril; e uma terceira época, intermediária, incluindo setembro, outubro, e novembro. Para a primeira época, favorável à obtenção de bom rendimento leiteiro e que coincide com a estação sêca, a média observada é 296,2 kg. Para a segunda, desfavorável à produção láctea, e que coincide, mais ou menos com a estação chuvosa, a média observada foi de $252,5 \mathrm{~kg}$.

O total das lactações iniciadas na estação sêca (maio, junho, julho e agosto), foi de $177.712,8 \mathrm{~kg}$., assim distribuido :

\begin{tabular}{c|c|c}
\hline Meses & Produção (kg) & Média mensal $(\mathrm{kg})$ \\
\cline { 2 - 3 } 1o. & $24.007,2$ & 400,1 \\
2o. & $21.521,4$ & 358,7 \\
3o. & $19.991,2$ & 333,2 \\
4o. & $19.055,8$ & 317,6 \\
5o. & $18.768,7$ & 312,8 \\
6o. & $18.032,8$ & 300,5 \\
$7 \mathrm{o}$. & $16.877,2$ & 281,3 \\
8o. & $14.996,6$ & 249,9 \\
$9 \mathrm{o}$. & $13.227,7$ & 220,5 \\
$10 \mathrm{o}$. & $11.234,2$ & 187,2 \\
\hline
\end{tabular}

O total das lactações iniciadas na estação chuvosa (dezembro, janeiro, fevereiro, março e abril) foi de : $189.382,2 \mathrm{~kg}$, com a seguinte distribuição:

\begin{tabular}{c|c|c}
\hline Meses & Produção $(\mathrm{kg})$ & Média mensal $(\mathrm{kg})$ \\
\hline & & \\
1o. & $27.665,7$ & 368,9 \\
2o. & $24.459,7$ & 326,1 \\
3o. & $22.044,5$ & 293,9 \\
4o. & $19.950,8$ & 266,0 \\
5o. & $18.174,3$ & 242,3 \\
6o. & $16.495,2$ & 219,9 \\
7o. & $16.023,6$ & 213,6 \\
8o. & $15.584,9$ & 207,8 \\
9o. & $14.901,9$ & 198,7 \\
10o. & $14.081,6$ & 187,0 \\
\hline
\end{tabular}




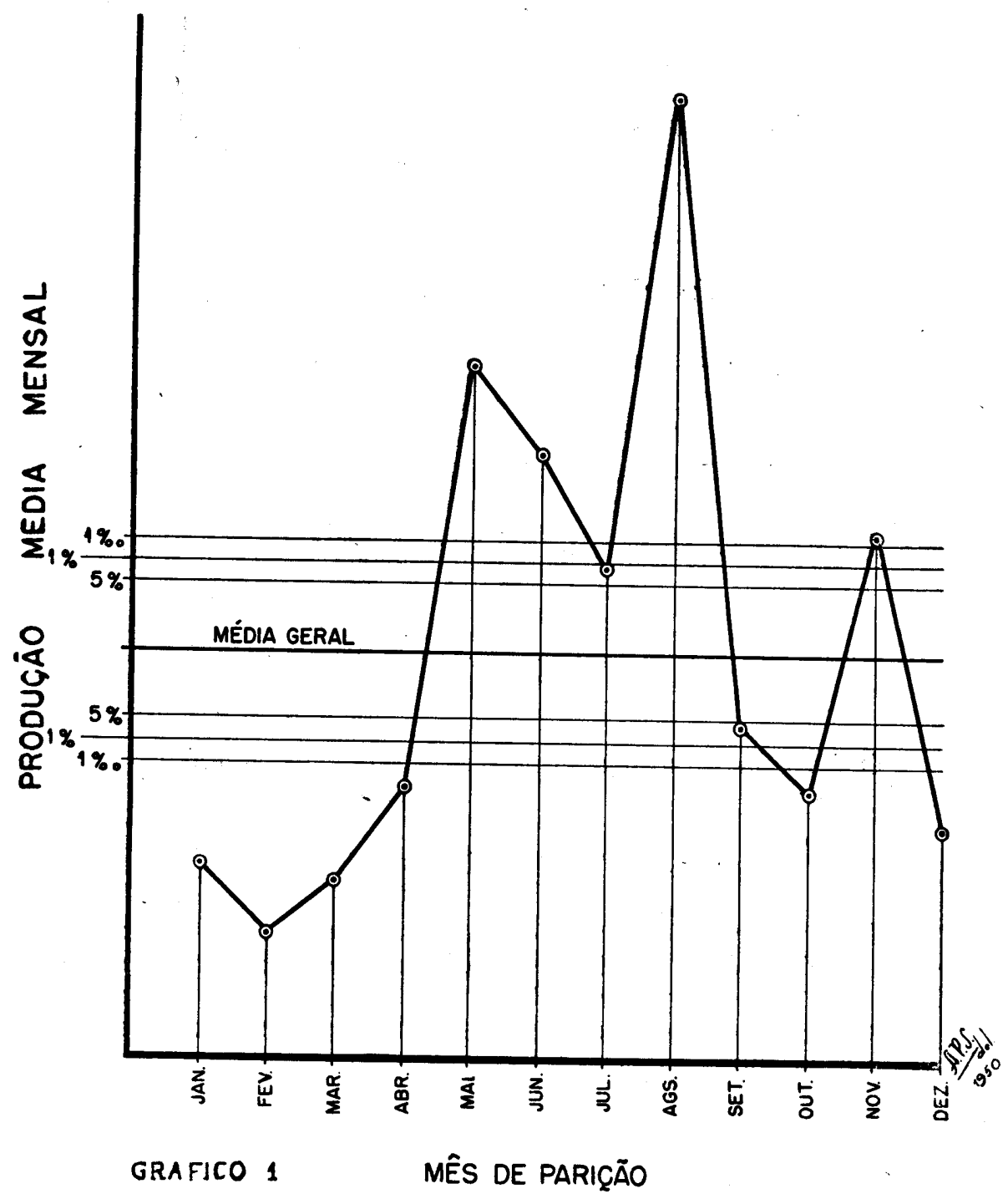




\section{6 - ESTAÇÕES DO ANO}

Fácil é calcular as médias de produção das quatro estações do ano. Os valores obtidos foram os seguintes:

\begin{tabular}{l|c}
\hline Estações & Média de produção (kg) \\
\cline { 1 - 2 } Primavera & 300,52 \\
Verão & 277,89 \\
Outono & 250,48 \\
Inverno & 255,09 \\
\hline
\end{tabular}

O êrro de cada uma dessas médias é :

$$
\sigma \overline{\mathrm{v}}=\frac{36,5}{\sqrt{450}}=1,72
$$

O êrro da diferença entre essas médias e a média geral, será pois :

$$
\sigma \text { dif. }_{0}=\sqrt{(1,72)^{2}+(0,86)^{2}}=1,92 .
$$

Esse valor nos permite concluir logo que tôdas as médias diferem da média geral $(270,99)$, mesmo tomando por base o limite de $1 \%$ o de probabilidade. Verifica-se, pois, que a Primavera é a estação mais favorável à lactação. A menos favorável é o outono.

\section{7 - MESES DE LACTAÇÃO}

A influência altamente significativa dos meses de lactação (de 30 dias), a partir do desaparecimento do colostro, devia ser esperada, evidentemente. Neste caso, porém, uma análise de covariância, tal como a seguinte, é aconselhável. 
Análise de covariância

\begin{tabular}{|c|c|c|c|c|c|}
\hline Causa de variação & $\Sigma(\mathrm{y}-\overline{\mathrm{y}})^{2}$ & $\mid \begin{array}{c}\Sigma(\mathrm{x}-\overline{\mathrm{x}}) \\
(\mathrm{y}-\overline{\mathrm{y}})\end{array}$ & $\Sigma(\mathrm{x} \cdot \overline{\mathrm{x}})^{2}$ & $\begin{array}{l}\text { Grau de } \\
\text { liberide }\end{array}$ & $\mathbf{r}$ \\
\hline $\begin{array}{l}\text { 1. Lactações (den- } \\
\text { tro do mês de } \\
\text { parição) } \\
\text { 2. Mês de parição } \\
\text { 3. Meses de lacta- } \\
\text { tação (de } 30 \\
\text { dias) } \\
\text { 4. Estações do ano } \\
\text { 5. Resíduo }\end{array}$ & $\begin{array}{r}8.591 .597,35 \\
844.511,59 \\
\\
7.196 .168,10 \\
961.479,26 \\
2.145 .718,83\end{array}$ & $\begin{array}{c}0 \\
0 \\
\\
-324475 \\
0 \\
0\end{array}$ & $\begin{array}{c}14.850 \\
0 \\
0\end{array} \mid$ & $\begin{array}{r}168 \\
11 \\
\\
9 \\
3 \\
1608\end{array}$ & $\begin{array}{c}- \\
- \\
-0,9926^{* * *} \\
-\end{array}$ \\
\hline Total & $19.739 .475,18$ & -324.475 & 14.850 & 1799 & $-0,5993^{* * *}$ \\
\hline
\end{tabular}

Vê-se que há uma correlação negativa altamente significativa, entre a produção leiteira $y$ e o tempo $x$ decorrido após a parição. Mas, o coeficiente de correlaçã̃o $r$ só é realmente elevado (- 0,9926) quando considerarmos a influência dos meses de lactação de 30 dias contados após o parto, sôbre a produção total de tôdas as vacas, em tôdas as estações do ano e em todos os meses de parição.

$\sigma$ dependente $=\sigma \mathrm{r}=894 \times 0,9926=887,4, \mathrm{~g}=1$,

$\sigma$ independente $=\sigma \cdot \overline{\mathrm{V} 1-\mathrm{r}^{2}}=894 \times 0,1214=$

Temos ainda :

$$
=108,53, \mathrm{~g}=8 \text {. }
$$

$$
\begin{aligned}
& \vartheta \text { dep./ res. }=\frac{887,4}{36,5}=24,3^{* * *}, \\
& \vartheta \text { ind } / \text { res. }=\frac{108,53}{36,5}=2,97^{* * *}, \\
& \vartheta \text { dep./ ind. }=\frac{887,4}{108,53}=8,2^{* * *} .
\end{aligned}
$$

Logo, a correlação não é estritamente linear, pois o segundo $\vartheta$ calculado é significativo, quando deveria ser insignifı- 
PRODUÇĀO MEDIA MENSAL

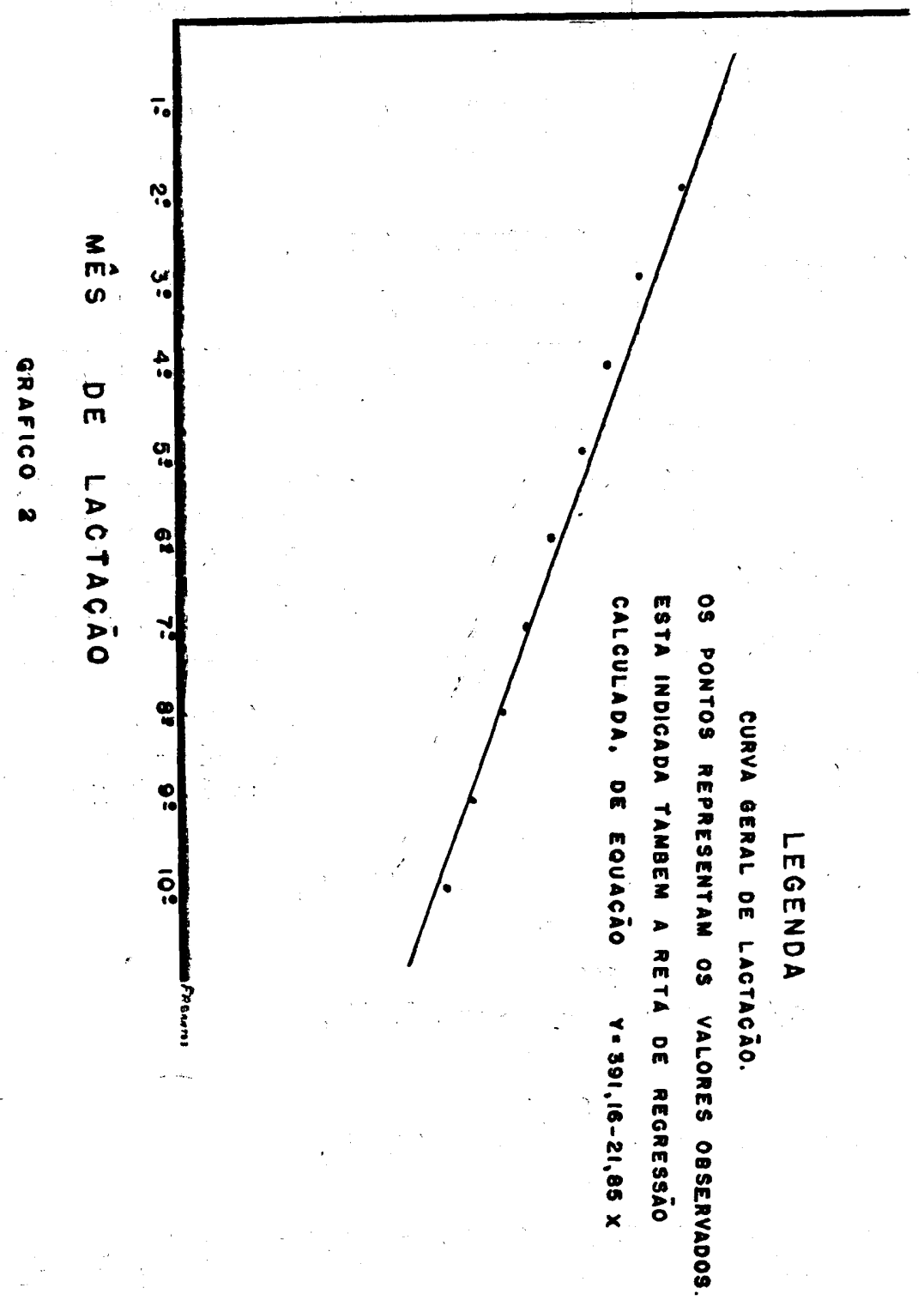


cante. Aliás, isso concorda com o gráfico 2 e ainda com os estudos de JORDĀO e PAULA ASSIS (11) sôbre o mesmo assunto, que discutiremos com maiores detalhes em outro artigo.

A produção média nos diversos meses de lactação de 30 dias, em números absolutos e relativos (média geral $=100$ ) dada a seguir :

\begin{tabular}{c|c|c}
\hline $\begin{array}{c}\text { Meses de lactação } \\
\text { (de 30 dias) }\end{array}$ & $\begin{array}{c}\text { Produção média } \\
\text { absoluta (kg) }\end{array}$ & $\%$ da média geral \\
\hline 1o. & 386,45 & 142,6 \\
2o. & 348,92 & 128,8 \\
3o. & 317,82 & 117,3 \\
4o. & 293,71 & 108,4 \\
5o. & 275,46 & 101,6 \\
6o. & 254,05 & 93,7 \\
70. & 237,55 & 87,7 \\
80. & 217,72 & 80,3 \\
90. & 198,33 & 73,6 \\
100. & 178,93 & 66,0 \\
\hline
\end{tabular}

A reta de regressão, que aparece no gráfico 2 , é dada pela equação:

$$
y-\vec{y}=b(x-\bar{x}),
$$

onde $x$ é o tempo em meses (de 30 dias) após o fim do perio do colostral, $y$ é a produção de leite em 30 dias, $\bar{x}$ é a média de $x$, y é a média de $y$ e $b$ é o coeficiente de regressão, dada pela formula :

$$
\mathrm{b}=\frac{\Sigma_{\mathrm{xy}}-\frac{\left(\Sigma_{\mathrm{x}}\right)\left(\Sigma_{\mathrm{y}}\right)}{\mathrm{N}}}{\Sigma_{\mathrm{x}^{2}}-\frac{\left(\Sigma_{\mathrm{x}}\right)^{2}}{\mathrm{~N}}}
$$

A aplicação desta fórmula nos dá :

$$
\mathrm{b}=21,85 \text {. }
$$

Como $\bar{x}=5,5$ e $\bar{y}=270,99$, obtemos fàcilmente, depois de feitas as simplificações,

$$
\mathrm{y}=391,16-21,85 \mathrm{x} \text {. }
$$

Esta é a equação da reta de regressão. 


\section{8 - DISCUSSÃO}

As condições climáticas e a alimentação não podem ser es. quecidas, quando se estuda a influência da época de parição e das estações do ano sôbre a secreção láctea, pois trata-se de fatores estreitamente relacionados entre si.

Segundo MORRISON (15), a temperatura do ar tem efejto sôbre o conteúdo do leite, talvez mais pronunciado que a própria fase de lactação. Quando o calôr é muito grande, isso pode causar uma franca redução no rendimento de leite, com um aumento no conteúdo de graxa e outras alterações em sua composição. Nas principais regiões leiteiras dos Estados Unidos, as vacas que parem no outono ou princípios de inverno (setembro a dezembro) e que são cuidadosamente alimentadas, rendem mais leite e matéria graxa do que aquelas que parem na primavera. Êsse rendimento chega a ser, em média, $11 \%$ mais elevado.

Ainda nos Estados Unidos, MAC DOWELL (14), analisou os resultados do contrôle leiteiro de 64 associações e chegou à conclusão de que as parições de outono garantiam um mais alto rendimento de leite. Seguiam-se, em ordem decrescente, as parıções de inverno, primavera e verão. $O$ mês mais favorável foi o de outubro, e o menos favorável o de janeiro. Em Iowa, (E. U. A.) CANON (6), baseando-se em milhares de dados das associações de contrôle leiteiro, mostrou que as vacas que parem em novembro apresentam maior rendimento.

Em Jamaica, os trabalhos de EDWARDS (8), vieram provar que as parições da estação sêca (dezembro a março), são mais favoráveis que as da estação chuvosa (maio a outubro). Sugere, porém, observações complementares, para que se possa chegar a uma conclusão definitiva sôbre o assunto nos climas tropicais.

Segundo LAHAYE (12), na Bélgica, a época de parição mais interessante vai de outubro a janeiro, sendo dezembro o mês mais favorável e junho o mais desfavorável.

$\mathrm{Na}$ Inglaterra, HAMMOND e SANDERS, (9), encontraram rendimentos mais elevados para as parições de outono. Verificaram, porém, uma larga variação de acốrdo com a região considerada, o que é explicado por influência da alimentação ligada a condiçõ̃es ambientais.

TUFF (18), na Suécia, assinalou os mais altos rendimentos para as parições de outubro, e os mais baixos para as de maio, e STRIBOLT (18), na Dinamarca cita no mesmo sentido, os meses de outubro e julho. 
LEROY (13), fazendo estudos na reglão do Seine e Oise (França), concluiu que se devem preferir as parições de inverno às de verão.

BONADONNA (2), observou no norte da Italia que é costume fazer coincidir as parições com o fim do outono ou com o inverno, afim de garantir uma lactação mais abundante:

Segundo ANDERSON (1), as vacas paridas no outono normalmente produzem um máximo rendimento em leite $\mathrm{e}$ matéria graxa. As parições de inverno são também superiores às da primavera e verão.

Entre nós, JORDÃO e PAULA ASSIS (11) estudando a persistência da produção leiteira no rebanho da Estação Experimental da Produção Animal em Pindamonhangaba chegaram a conclusão, no que concerne à raça Holandesa Malhada de Preto, de que as lactações iniciadas nos meses de temperatura ambiente mais fria, correspondentes à estação sêca, mostraram nível de produção mais elevado do que as lactações começadas nos meses mais quentes e úmidos.

TORRES (9), citando PARISI, dá para a França e Dinamarca, outubro como o mês de parição mais favorável a u'a maior produção, e acrescenta não possuirmos dados' relativos ao nosso estado, mas que, provàvelmente, entre nós, aquela época seria um ou dois meses antes.

De um modo geral, pode-se observar que a maioria dos autores assinala duas épocas de parição, as quais, para o clima tropical, tornam-se bem distintas : a estação da sêca, mais favorável e a estação das chuvas, menos favorável. A influência de tais períodos se faz sentir não só através dos fatores climatéricos, como temperatura, umidade, etc., mas também através da alimentação.

As nossas pesquisas confirmam, de u'a maneira geral, o que acima foi exposto. A estação sêca foi, de fato, a mais interessante para o início das lactaçōes, cuja média mensal de produção foi de $296,2 \mathrm{~kg}$ de leite, $17,3 \%$ mais elevada que a média observada para a estação das águas, de $252,5 \mathrm{~kg}$. De fato, as vacas paridas no fim do outono, ou durante o inverno, apresentam um decréscimo de produção menos acentuado, como se pode verificar pelo gráfico 3 , onde apresentamos as curvas de lactação em estudo. A explicação daquele fato deve ser procurada na fisiologia da secreção. Dois são os fatores que estimulam a secreção láctea : a ação dos hormônios, e a reação nervosa decorrente do trato e alimentação recebida pelo animal. O estímulo hormônico predomina após a parição, e atua mais ou menos independentemente da alimentação. Com o de- 
correr do período de lactação, a influência dos hormônios vai sendo gradualmente substituida pelo estímulo nervoso. Assim, as vacas que parem na sêca, conseguem atravessar êsse periodo com bôa produção, graças a atividade dos hormônios; quando a ação dêstes começa a decrescer, as primeiras chuvas da primavera fazem rebrotar as pastagens, e a alimentação "verde" vai aos poucos se tornando mais abundante.

Agosto foi o mês de parição mais favorável. A produção média das lactações iniciadas nesse mês foi de $320,8 \mathrm{~kg}$ de lcite. São também dignas de registro, em ordem decrescente de produção, as parições de maio, junho e julho.

Das lactações iniciadas na época das chuvas, as de fevereiro apresentaram a mais baixa média de produção: $245,9 \mathrm{~kg}$. No gráfico 3 pode-se observar que, de início, as curvas de lactação (da época sêca e da época das águas) apresentam pequena diferença, mas, com o decorrer do período, nota-se uma flagrante superioridade das lactações da época sêca. $O$ fato é que, se de um lado há uma soma de condições favoráveis (hormônios e alimentação) no início das lactações da estação chuvosa, por outro lado, verifica-se uma soma de condições desfavorávéis no fim do período, isto é, a queda natural da secreção aliada à época de sêca, que o animal atravessa por tempo mais ou menos longo. A sêca é, portanto, mais prejudicial no fim da lactação que no início, quando a produção de leite está garantida pela potência hormônica, que a vaca recebe após a parição e também pelas reservas acumuladas em seu organismo.

A queda da produção leiteira durante a lactação não obedece a uma regressão absolutamente linear, mas a hipótese da linearidade dá uma bôa aproximação. Estudos mais detalhados a êsse respeito serão apresentados num trabalho próximo. No momento, porém, já podemos dizer, com base na equação de regressão obtida,

$$
y=391,16-21,85 x
$$

que a queda mensal média na produção de leite das vacas de raça Holandesa estudadas, é de $21,85 \mathrm{~kg}$ de leite, o que corresponde a $8,06 \%$ da média geral do rebanho. 


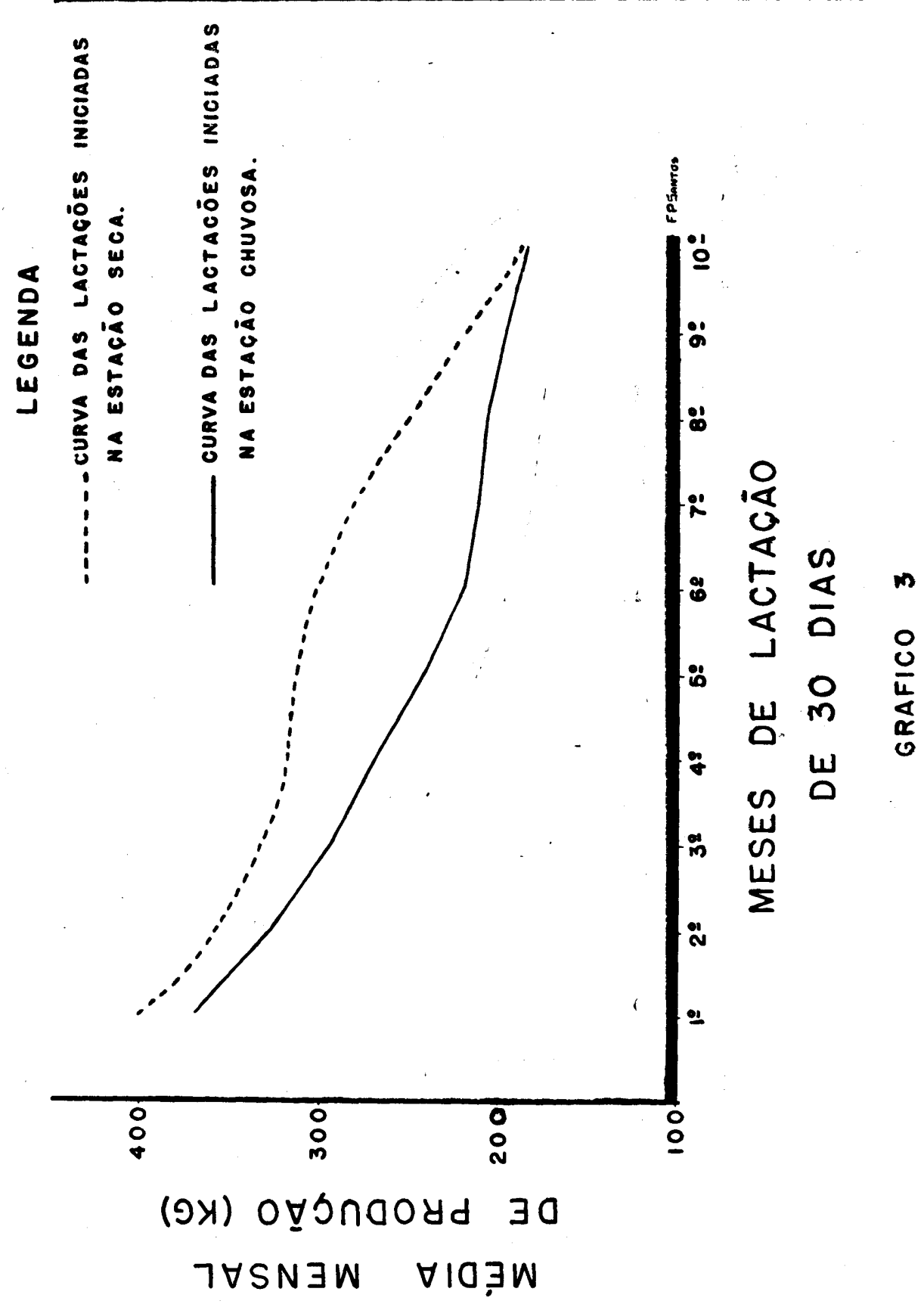




\section{9 - RESUMO E CONCLUSÕES}

Estudando a influência da época de parição, estações do ano e meses de lactação, sôbre a produção de leite, no rebanho Holandês Malhado de Preto do Pôsto Zootécnico da Eiscola Superior de Agricultura "Luiz de Queiroz", chegamos às seguintes conclusões:

1. A época mais favorável para o início das lactações é a estação sêca, que abrange os meses de maio, junho, julho e agosto. A média mensal de produção das lactações começadas naquela estação foi de $296,2 \mathrm{~kg}$ de leite, $17,3 \%$ mais elevada que a alcançada pelas lactações da estação das águas, $252,5 \mathrm{~kg}$.

2. O mês mais favorável à parição é agosto. As lactações iniciadas nesse mês apresentaram u'a média de $320,8 \mathrm{~kg}$ de leite. Fevereiro é o mês mais desfavorável com produção média de $245,9 \mathrm{~kg}$.

3. A primavera se revela a estação mais favorável à lactação, com produção média mensal de $300,52 \mathrm{~kg}$. A estação menos interessante é o outono com u'a média de produção mensal de $250,48 \mathrm{~kg}$.

4. Existe influência altamente significativa dos meses de lactação de trinta dias (contados a partir do desaparecimento do colostro) sôbre a produção de leite. Há uma correlação negativa altamente significante entre a produção leiteira $y$ e o tempo $x$, decorrido após a parição. Essa correlação não é estritamente linear, mas a hipótese de linearidade dá una bia aproximação. A equação de regressão é

$$
\mathrm{Y}=391,10-21,85 \mathrm{x}
$$

de onde se conclue que há, durante a lactação, uma queda mensal média de $21,85 \mathrm{~kg}$ de leite, o que corresponde a $8,06 \%$ da média geral do rebanho.

\section{0 - ABSTRACT}

The authors studied the effects of calving time, season and time elapsed after calving on milk production of the Holstein Friesian Breed of the "Escola Superior de Agricultura "Luiz de Queiroz" (Piracicaba, Brasil), 180 lactation periods of 300 days were studied, with 15 calvings in each month. Statistical analysis of the data proved:

1. That calving in May, June, July or August, that is, in the driest months, the cows give a milk production $17,3 \%$ larger than calving in December, January, February, March or 
April. August is the best month for calving, and February is the worst.

2. Spring is the most favorable, and Autumn the most unfavorable season for milk production.

3 . The decrease of milk production during the lactation period depends largely on calving time. But, on the whole, linear regression can be used as a good aproximation, with a correlation coefficient $\mathbf{r}=-0,9926$ and a monthly decrease, per month elapsed after calving, of 8,06 percent of the general mean.

4. Diagram 1 shows the effects of calving month on milk production. The limits of $5 \%, 1 \%$ and $1 \% 0$ of probabilities are given there.

\section{BIBLIOGRAFIA}

1-ANDERSON, A. L. - Introductory Animal Husbandry. Macmillan Co. N. York - 1943.

2-BONADONNA, T. - Zootecnica Especiale. Vol. Primo. Instituto Editoriale Cisalpino - Milão - 1946.

3-BRIEGER, F. G. - Tábuas e Fórmulas para Estatística. Cia. Melhoramentos - São Paulo - 1947 .

4-BRIEGER, F. G. - Limites Unilaterais e Bilaterais na Análise Estatística. Bragantia 6: 479-545 - 1946.

5-BRIEGER, F. G. - Análise da Correlação e Covariância - Piracicaba - 1950.

6-CANNON, C. Y. - Cit in Lahaye, J. J. Marcq e E. Cordiez. Les Bovins. Alimentation du Betail - Tome II. 3a. ed. Gembloux - 1946.

7-ECKLES, C. H., E. L. Anthony e L. S. Palmer - Dairy Cattle and Milk Production. Macmillan Company. 3a. ed. N. York - 1939.

8-EDWARDS, J. - Breeding for milk production in the tropics. The Jornal of Dairy Research. 3-281 - 1932.

9- HAMMOND, J., G. Sanders - Cit. in Marq, J. e Devuyst. Époque de la mise-bas en relation avec la production laitière et l'élevage chez les bovins, Bull. de l'Institut. Agron. de Gembloux - Tome III. n. 1 - 1934.

10-HENDERSON, H. O., C. W. Larson e F. S. Putney - La vaca lechera. Ver. Cast. 3a. ed. U. T. E. H. A. A. México 1950 
11 - JORDÃO, L. P. e F. Paula Assis - Persistência da Produção Leiteira no Rebạnho da Estação Experimental de Produção Animal, Pindamonhangaba. Bol. Ind. Animal, São Paulo - Vol. 10 N. único: 5-29. 1948-49.

12 - LAHAYE, J., J. Marcq e E. Cordiez - Les Bovins. Alimentation du Bétail. Tome II - 2a. ed. Gembloux 1946.

13 - LEROY, A. M. - Cit. in Marcq, J. e Devuyst. Epoque de la mise-bas en relation avec la production laitière et l'élevage chez les bovins. Bull. de l'Institut Agron. de Gemblóux. Tome III, n. $1-1934$.

14 - MAC DOWELL - Cit. in Lahaye J., Marcq e E. Cordiez. Les Bovins. Alimentation du Bétail. Tome II - 2a. ed. Gembloux - 1946.

15-MORRISON, F. B. - Alimentos y Alimentacion. Vers. Cast. 20a. ed. Santiago del Chile - 1943.

16 - PIMENTEL GOMES, Frederico - Como varia durante o ano a porcentagem de gordura do leite em Piracicaba. Rev. de Agricultura - Piracicaba. Vol. 18. Nos. 9-10: 319-333 - 1943.

17 - PIMENTEL GOMES, Frederico - Notas sôbre a teoria da correlação. Piracicaba - 1950.

18 - STRIBOLT e Tuff - Cit. in Lahaye, J. e J. Marcq e E. Cordiez. Les Bovins. Alimentation du Bétail. Tome II. 2a. ed. Gembloux - 1946.

19 - TORRES, A. P. - Melhoramento dos Rebanhos. Cia Melhoramentos. São Paulo - 1947. 